\title{
Periventricular heterotopia and white matter abnormalities in a girl with mosaic ring chromosome 6
}

\author{
Satsuki Nishigaki ${ }^{*}$, Takashi Hamazaki $^{1}$, Mika Saito ${ }^{1}$, Toshiyuki Yamamoto ${ }^{2}$, Toshiyuki Seto ${ }^{1}$ and Haruo Shintaku ${ }^{1}$
}

\begin{abstract}
Ring chromosome 6 is a rare chromosome abnormality that arises typically de novo. The phenotypes can be highly variable, ranging from almost normal to severe malformations and neurological defects. We report a case of a 3-year-old girl with mosaic ring chromosome 6 who presented with being small for gestational age and intellectual disability, and whose brain MRI later revealed periventricular heterotopia and white matter abnormalities. Mosaicism was identified in peripheral blood cells examined by standard G-bands, mos 46,XX,r(6)(p25q27)[67]/45,XX,-6[25]/ 46,XX,dic r(6:6)(p25q27:p25q27)[6]/47,XX,r(6)(p25q27) × 2[2]. Using array-comparative genomic hybridization, we identified terminal deletion of $6 \mathrm{q} 27(1.5 \mathrm{Mb})$ and no deletion on 6p. To our knowledge, this is the first report of periventricular heterotopia and white matter abnormalities manifested in a patient with ring chromosome 6 . These central nervous system malformations are further discussed in relation to molecular genetics.
\end{abstract}

Keywords: Ring chromosome 6, Brain MRI, Periventricular heterotopia, White matter abnormality, Array-comparative genomic hybridization, Small for gestational age

\section{Background}

Ring chromosome 6 is a rare chromosome abnormality that arises typically de novo [1]. The phenotypes can vary from almost normal to severe malformations and mental defects [2]. The most common clinical features include intellectual disability, microcephaly, prenatal growth failure, retarded bone age, short neck, and typical facial anomalies [3]. As for brain abnormalities, hydrocephalus is the most important prenatal feature [4]. In addition to cortical atrophy and ventriculomegaly, absence of olfactory tract, agenesis or hypoplasia of the corpus callosum, aqueduct stenosis, and neuronal migration defects are also observed in previous reports [5].

Here, we report a case of mosaic ring chromosome 6 in a 3-year-old girl who presented with failure to thrive, microcephaly, and developmental delay and whose brain magnetic resonance imaging (MRI) later revealed periventricular heterotopia and white matter abnormalities. Neither of these central nervous system anomalies

\footnotetext{
* Correspondence: nishigaki.satsuki@med.osaka-cu.ac.jp

'Department of Pediatrics, Osaka City University Graduate School of

Medicine, 1-4-3 Asahi-machi, Abeno-ku, Osaka 545-8585, Japan

Full list of author information is available at the end of the article
}

has been previously reported in association with ring chromosome 6.

\section{Case presentation}

\section{Clinical description}

The patient, a female, is the second child of healthy unrelated parents. Family history, including her 4-year-old sister, was unremarkable. This patient was born by means of caesarean delivery because of intrauterine growth retardation at the 39th week of gestation. Birth weight was $1,785 \mathrm{~g}(<-2 \mathrm{SD})$, length was $43 \mathrm{~cm}(<-2 \mathrm{SD})$ and head circumference was $29 \mathrm{~cm}(<-2 \mathrm{SD})$. Apgar scores were 8 and 9 at 1 and 5 minutes, respectively. She was able to sit at 5 months, walk at 14 months. Although at age 3 years she couldn't speak in two-word sentences, at age 3 years and 11 months she was able to speak threeword sentences with postpositions. She had a history of repeated febrile seizures.

At the age of 3 years and 11 months, her weight was $9,300 \mathrm{~g}(-3 \mathrm{SD})$, length $89.7 \mathrm{~cm}(-2.4 \mathrm{SD})$ and head circumference $41.3 \mathrm{~cm}(-4.4 \mathrm{SD})$. Short stature prompted endocrinological investigations and karyotyping. Exaggerated growth hormone responses to arginine, levodopa and 
clonidine stimulation were within normal range, whereas karyotype analysis revealed mosaic ring chromosome 6 (Fig. 1). She presented minor dysmorphic features including full lips and epicanthal folds. Ophthalmological and otological including aural examination were normal, and ultrasound cardiac examination revealed no anomalies. Kyoto Scale of Psychological Development, which is a standardized developmental test for Japanese children, was performed at 3 years 10 months, revealing postural-motor skills of 3 years 1 month (subquotient 79), cognitive-adaptive skills of 2 years 6 months (subquotient 64), language-social skills of 2 years 9 months (subquotient 70), and overall developmental age of 2 years 8 months (developmental quotient 68).

Cerebral MRI revealed periventricular heterotopia on the bilateral posterior horn of the lateral ventricle and white matter abnormalities in the bilateral parietal and occipital lobe. Neither hydrocephalus nor enlarged lateral ventricles were detected (Fig. 2). Electroencephalogram (EEG) during induced sleep showed poor normal sleep spindles and slightly irregular background activity in the bilateral occipital head regions. The possibility of tuberous sclerosis was also considered with respect to the observed periventricular nodules. Besides the past episodes of febrile seizure, she never had an epileptic attack, and anticonvulsant agent was never prescribed, ruling out the possibility of tuberous sclerosis. This study was approved by institutional review board (Osaka City University).

\section{Molecular and cytogenomic characterization}

This study was conducted following approval by the ethics committee at our institution. After obtaining the written informed consent from the patient's family, blood sample was drawn from the patient. Chromosome analysis was performed on peripheral blood lymphocyte cultures. Standard G-bands analysis revealed mos 46,XX, r(6)(p25q27)[67]/45,XX,-6[25]/46,XX, dic r(6:6)(p25q27: p25q27)[6]/47,XX,r(6) (p25q27) × 2[2]. The microarraybased comparative genomic hybridization (array-CGH) analysis was performed as described previously [6] and revealed a genomic copy number loss at 6q27 (Fig. 3).

\section{Discussion}

In general, ring chromosomes are formed by fusion of the distal ends in both arms and often lose genomic material of the terminal ends. The rings may result in clinical features mimicking terminal deletion syndromes. On the other hand, a patient carrying a ring chromosome 6 without terminal deletions has been reported with short stature and minor dysmorphisms but with normal psychomotor development [7]. This indicates that carrying a ring chromosome itself may lead to these clinical features. These prenatal and postnatal growth failures, also seen in the present case, are common features of any autosome ring chromosome. It has been suggested that this is due to the mitotic instability of rings, preventing normal cellular proliferations $[8,9]$.

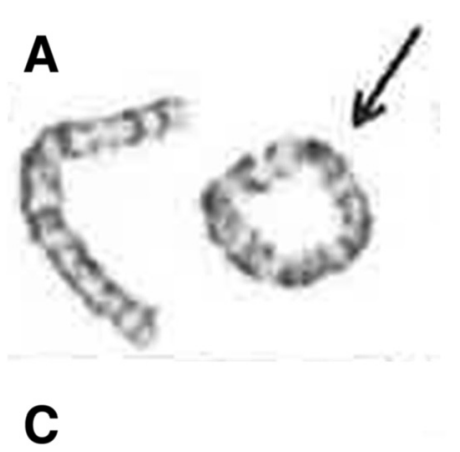

B

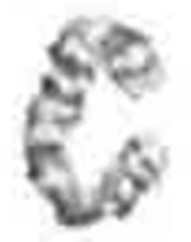

D
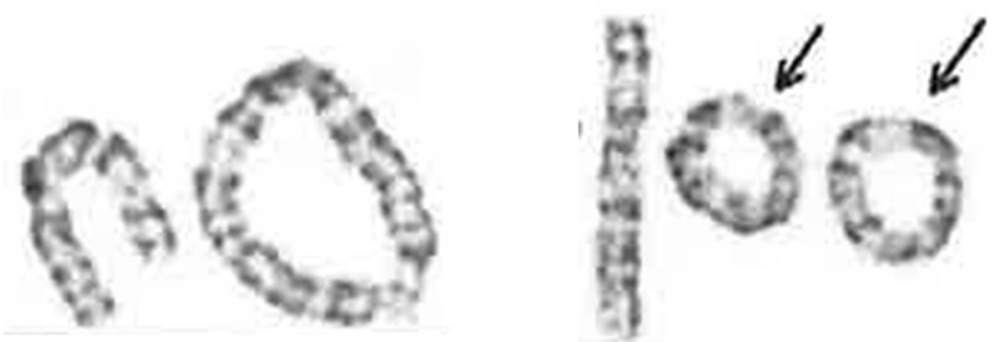

Fig. 1 Chromosome G-banding result from the patient. The total number of cells counted was hundred. a Ring chromosome (67 \%). b Monosomy 6 (25\%). c Dicentric ring chromosome (6\%). d Double ring chromosome (2\%) 

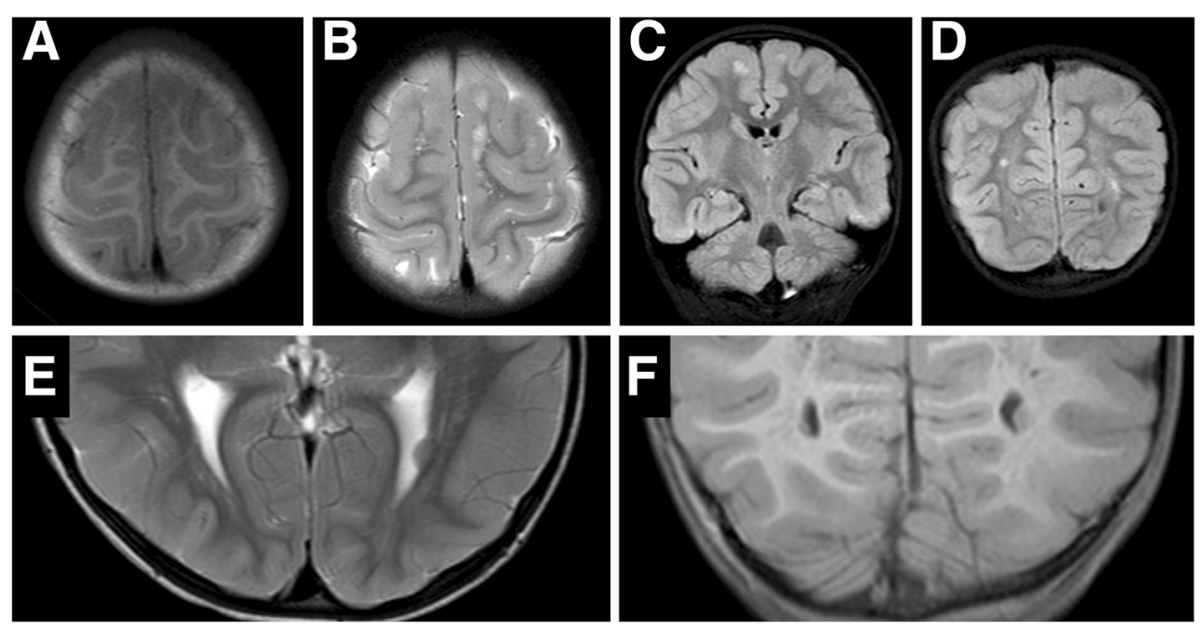

Fig. 2 a-f: MRI imaging of the brain of this patient. $\mathbf{a}$ and $\mathbf{b}$ Axial T1W and T2W image, showing left parietal lobe. c Coronal T2W section showing white matter abnormalities in the bilateral parietal lobe. $\mathbf{d}$ Coronal T2W section showing white matter abnormalities in the bilateral occipital lobe. $\mathbf{e}$ and $\mathbf{f}$ Axial and Coronal FLAIR image, showing periventricular heterotopia on the bilateral posterior horn of the lateral ventricle

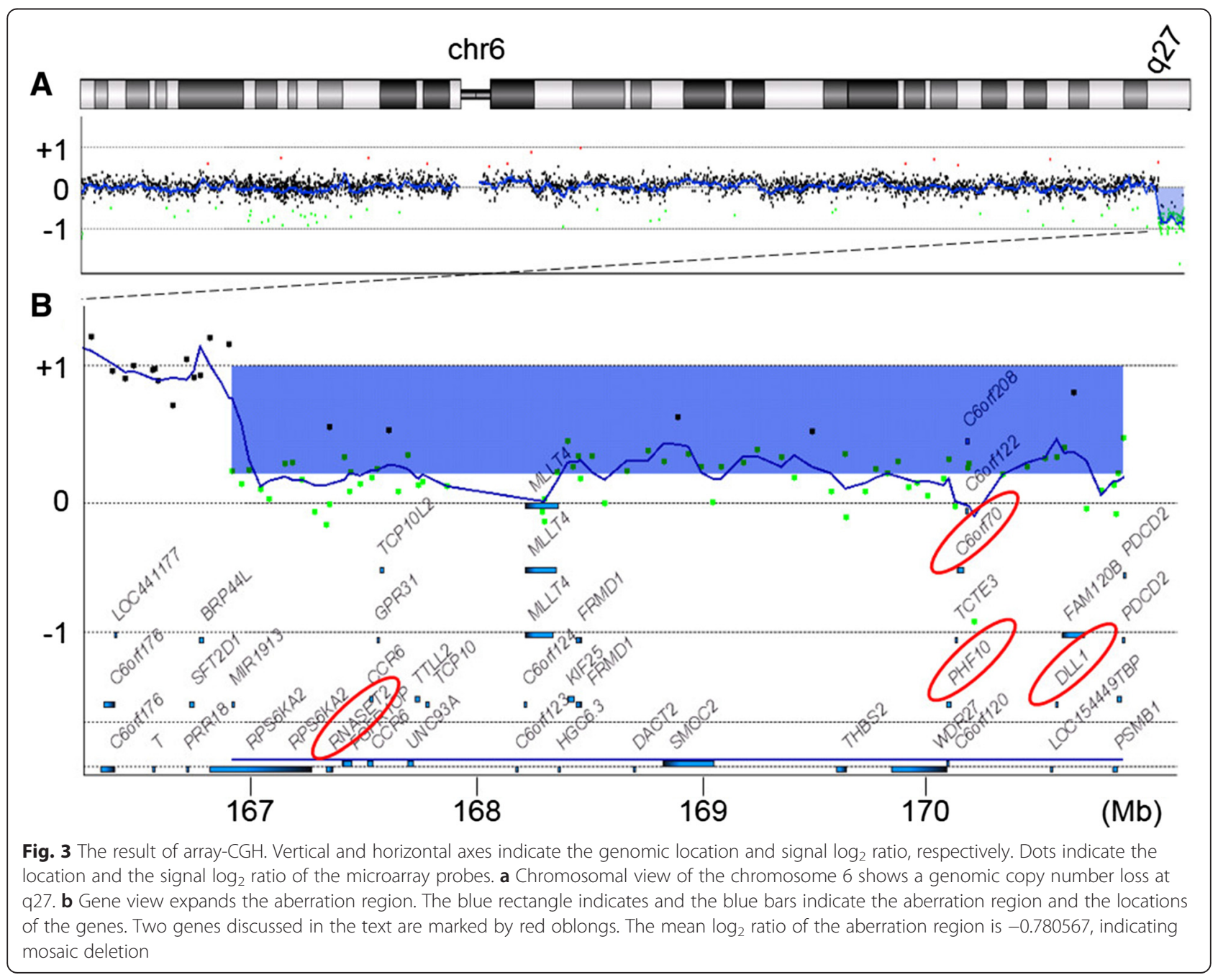


Terminal deletion on $6 \mathrm{q}$ has been linked to certain brain abnormalities as well as neurological signs and symptoms. Based on a series of the array-CGH analysis, Eash et al. have suggested that the terminal region of chromosome $6 \mathrm{q}$ is a critical area for intellectual disability, hydrocephalus, abnormal corpus callosum, seizures, and hypotonia [10]. In the present case where the terminal of 6q27 was deleted, none of those clinical features was present except for intellectual disability.

A few studies have investigated the effects of terminal deletion on 6p. In an adult case report, chromosome 6p subtelomeric deletions were thought to be a possible underlying cause for periventricular white matter abnormalities [11]. Another study found that the most consistent clinical features in the patients with 6p25 deletion included developmental delay, intellectual disability, language impairment, hearing loss, ophthalmologic, cardiac, and craniofacial abnormalities [12]. In the present case where 6 p25 was intact, the patient presented with developmental delay, intellectual disability, and language impairment but had neither hearing loss nor ophthalmologic/cardiac abnormalities.

C6orf70 is a gene that maps on 6q27 and is one of the deleted genes in this patient (Fig. 3). Haploinsufficiency of C6orf70 is surmised to play a major role in the pathogenesis of periventricular heterotopia in this patient. Haploinsufficiency or mutation of C6orf70, has recently been suggested as the main cause of the brain malformation complex including periventricular heterotopia [13]. C6orf70 is expressed in developing human brain and is involved in neuronal migration. However, in the previous reports of ring chromosome 6 with 6q27 deletions including C6orf70, periventricular heterotopia has not been pointed out $[5,14]$.

Regarding the white matter abnormality found in this patient, contiguous gene deletions on $6 \mathrm{q} 27$ may play a role. Contiguous gene deletion of PHF1O and DLL1 could be an underlying mechanism of the white matter abnormality observed in this patient (Fig. 3). Conti et al. experimentally demonstrated that down-regulation of PHF10 and DLL1 expression in utero delayed neuronal migration in a rodent model [13]. Additionally, RNASET2, which is also mapped within the deleted region in the present case (Fig. 3), was reported to have an association with familial cystic leukoencephalopathy [15]. RNASET2 encodes a putative lysosomal hydrase and the loss of function in zebrafish caused accumulation of amyloid precursor protein in the brain [16].

\section{Conclusions}

This is the first report of periventricular heterotopia and white matter abnormalities manifested in a patient with ring chromosome 6 . Further accumulation of cases with similar deletion in this region of chromosome 6 will identify the genes responsible for this neurological phenotype.

\section{Consent}

Written informed consent was obtained from the parents of the patient for publication of this Case report and any accompanying images. A copy of the written consent is available for review by the Editor-in-Chief of this journal.

\section{Abbreviations}

MRI: Magnetic Resonance Image; array-CGH: Microarray-based comparative genomic hybridization; EEG: Electroencephalogram.

\section{Competing interests}

The authors declare that they have no competing interests.

\section{Authors' contributions}

MS and TS referred the patient for this study and coordinated the clinical analysis of the patient. SN, TH and TS were responsible for the patient's clinical genetic examination. MS and HS contributed to the clinical description. TY performed the array CGH and analyzed the data. All authors co-wrote the manuscript. TH and TY revised the manuscript critically for important intellectual content. All authors read and approved the final manuscript.

\section{Author details}

'Department of Pediatrics, Osaka City University Graduate School of Medicine, 1-4-3 Asahi-machi, Abeno-ku, Osaka 545-8585, Japan. 'Institute for Integrated Medical Sciences, Tokyo Women's Medical University, 8-1 Kawada-cho, Shinjuku-ward, Tokyo 162-8666, Japan.

Received: 16 April 2015 Accepted: 12 July 2015

Published online: 26 July 2015

\section{Reference}

1. Ahzad HA, Ramli SF, Loong TM, Salahshourifar I, Zilfalil BA, Yusoff NM. De novo ring chromosome 6 in a child with multiple congenital anomalies. Kobe J Med Sci. 2010;56(2):E79-84.

2. Lee SJ, Han DK, Cho HJ, Cho YK, Ma JS. Mosaic ring chromosome 6 in an infant with significant patent ductus arteriosus and multiple congenital anomalies. J Korean Med Sci. 2012;27:948-52.

3. Kini KR, Van Dyke DL, Weiss L, Logan MS. Ring chromosome 6: case report and review of literature. Hum Genet. 1979;50(2):145-9.

4. Urban M, Bommer C, Tennstedt C, Lehmann K, Thiel G, Wegner RD, et al. Ring chromosome 6 in three fetuses: case reports, literature review, and implications for prenatal diagnosis. Am J Med Genet. 2002;108:97-104.

5. Zhang HZ, Li P, Wang D, Huff S, Nimmakayalu M, Qumsiyeh M, et al. FOXC1 gene deletion is associated with eye anomalies in ring chromosome 6. Am J Med Genet A. 2004;124A(3):280-7.

6. Yamamoto T, Shimojima K, Nishizawa T, Matsuo M, Ito M, Imai K. Clinical manifestations of the deletion of down syndrome critical region including DYRK1A and KCNJ6. Am J Med Genet A. 2011;155:113-9.

7. Höckner M, Utermann B, Erdel M, Fauth C, Utermann G, Kotzot D. Molecular characterization of a de novo ring chromosome 6 in a growth retarded but otherwise healthy woman. Am J Med Genet A. 2008;146:925-9.

8. Sodré CP, Guilherme RS, Meloni VFA, Brunoni D, Juliano Y, Andrade JAD, et al. Ring chromosome instability evaluation in six patients with autosomal rings. Genet Mol Res. 2010;9:134-43.

9. Kosztolányi G. Does "ring syndrome" exist? An analysis of 207 case reports on patients with a ring autosome. Hum Genet. 1987;75:174-9.

10. Eash D, Waggoner D, Chung J, Stevenson D, Martin CL. Calibration of $6 \mathrm{q}$ subtelomere deletions to define genotype/phenotype correlations. Clin Genet. 2005;67:396-403.

11. Vernon HJ, Bytyci Telegrafi A, Batista D, Owegi M, Leigh R. $6 p 25$ microdeletion: white matter abnormalities in an adult patient. Am J Med Genet A. 2013;161:1686-9.

12. Descipio C. The $6 p$ subtelomere deletion syndrome. Am J Med Genet C Semin Med Genet. 2007;145:377-82 
13. Conti V, Carabalona A, Pallesi-Pocachard E, Parrini E, Leventer RJ, Buhler E, et al. Periventricular heterotopia in $6 \mathrm{q}$ terminal deletion syndrome: role of the C6orf70 gene. Brain. 2013;136:3378-94.

14. Ciocca L, Surace C, Digilio MC, Roberti MC, Sirleto P, Lombardo A, et al. Array-CGH characterization and genotype-phenotype analysis in a patient with a ring chromosome 6. BMC Med Genomics. 2013;6:3.

15. Henneke M, Diekmann S, Ohlenbusch A, Kaiser J, Engelbrecht V, Kohlschütter A, et al. RNASET2-deficient cystic leukoencephalopathy resembles congenital cytomegalovirus brain infection. Nat Genet. 2009:41:773-5.

16. Haud N, Kara F, Diekmann S, Henneke M, Willer JR, Hillwig MS, et al. RNASET2 mutant zebrafish model familial cystic leukoencephalopathy and reveal a role for RNase T2 in degrading ribosomal RNA. Proc Natl Acad Sci U S A. 2011;108:1099-103.

\section{Submit your next manuscript to BioMed Central and take full advantage of:}

- Convenient online submission

- Thorough peer review

- No space constraints or color figure charges

- Immediate publication on acceptance

- Inclusion in PubMed, CAS, Scopus and Google Scholar

- Research which is freely available for redistribution 